\title{
Fabrication of composite heat sinks consisting of a thin metallic skin and a polymer core using Wire-Arc spraying
}

\author{
Chen Feng, Michael Gibbons, Sanjeev Chandra \\ Centre for Advanced Coating Technologies, \\ University of Toronto \\ Ontario, Canada M5S 368
}

\begin{abstract}
Three composite heat sinks in the shape of a disk, a cylinder, and a cylinder with vertically projecting fins were made by applying a thin $(0.4-0.7 \mathrm{~mm})$ zinc layer onto ABS polymer cores using wire-arc spraying. The influence of spray distance and surface roughness on the adhesion strength between the zinc and ABS layers were investigated and a maximum adhesion strength of 2.6 MPa was obtained. An analytical model of the heat conduction in an annular fin was developed, assuming one-dimensional heat conduction in the metal coating and twodimensional conduction in the polymer core. The temperature distribution along the disk-shaped heat sink was measured using an infra-red camera and found to agree well with the developed model. The calculated temperatures at the base of the heat sink also agreed with measured values as heater power was varied. The model was used to examine the effect of fin radius and coating thickness on fin efficiency.
\end{abstract}

Keywords: heat sinks; electronic cooling; analytical model; fin efficiency; heat transfer. 


\section{Introduction}

Finned heat sinks are commonly used to increase the effective surface area of an electronic component, enhancing the rate of heat dissipation to the surrounding air. An external heat sink is usually required to be mounted to the back of light emitting diode (LED) chips in order to dissipate the heat generated by them when operating. The light output and lifecycle of LEDs decrease as their operation temperature rises [1] [2]. Heat sinks are typically made of high thermal conductivity metals such as copper or aluminum, and for small LED light fixtures they can constitute a significant portion of the total cost and weight of the hardware [3] [4]. This has led to the development of lightweight heat sinks made of composite materials, usually polymers filled with metal or graphite in the form of powders, flakes or wires [3] [5],. Though the effective thermal conductivity of the composites is much lower than that of pure metal, it is adequate for applications that do not require high heat fluxes. An alternate method of making a composite cooling device that has been proposed [6] is to make the heat sink out of polymer and insert aluminum components into it to provide heat conduction paths. Numerical simulations have shown that such a device could reduce the junction temperatures of LED bulbs, with the metal inserts significantly enhancing heat transfer. However, this requires the fabrication of metal parts, which adds to their cost and limits how thin they can be made.

Different designs of composite heat sinks have been tested for thermal management of electronic devices [3],[6],[7],[8]. Yang et al.[3] used vacuum pressure casting to manufacture finned heat sinks for LEDs from a mixture of graphite and metal powders. These composite heat sinks had heat transfer capacities comparable to those of aluminum alloy heat sinks, but were lighter and had a lower cost. Arshad et al. [8] enhanced the passive cooling of aluminum finned heat sinks by filling them with paraffin wax that acted as a phase change material. Stark et al. [9] proposed a novel composite annular fin design consisting of alternating layers of metal fins and open-cell, high-porosity metal foams. Composite fins are also used in industrial applications such as heat exchangers, typically when a coating is applied to a metallic fin to protect it from corrosion [10]. In galvanizing or aluminizing technologies steel fins are coated with a thin layer of zinc or aluminum to prevent corrosion [11]. 
The rate of heat transfer from a heat sink corresponds to its surface area, which varies proportionately with the square of its length. However, its volume increases proportionately to the cube of its length. Therefore, scaling up the size of a heat sink results in a significant weight increase. A promising solution to this problem is to construct the heat sink structure of a lightweight material, which may have a low thermal conductivity, and placing a high thermal conductivity material on its surface to serve as a route for heat transfer. The exposed surface area of the high thermal conductivity material can be maximized in this way.

In this paper we study a novel method of making a composite heat sink, consisting of a polymer structural support on which a thin metal coating was applied using wire-arc spraying to provide a heat conduction path. In such a design the shape of the polymer components can be designed to maximize the surface area and guide air-flow so as to enhance natural convection while the metal layer reduces resistance to heat conduction and also maximize heat transfer to the surrounding air. The thickness of the metal layer can be controlled to make its thermal resistance small compared to that of the natural convection boundary layer: since the conductive and convective thermal resistances are in series, applying more metal will provide little additional enhancement of heat transfer. This approach optimizes the heat transfer surface area while minimizing the weight and cost of the fins. However, metallization of polymers using thermal sprays is a challenging process due to the complex deposition mechanisms. Unlike its metal on metal counterpart, metal coating of polymer substrates is an immature technology [12],[13]. However, it has tremendous potential in low power thermal dissipation applications.

The objectives of this study are to: (a) develop a method of depositing a thin metal coating on a polymer substrate; (b) study the influence of spray distance and surface roughness on adhesion strength of zinc coating on acrylonitrile butadiene styrene (ABS) surfaces; (c) measure the rate of heat transfer from a circular, composite fin heated at its center; (d) develop and validate an analytical model of heat conduction through the composite fin and (e) use the model to design and test cylindrical composite heat sinks. Through this methodology, this work seeks to be the first to demonstrate the efficacy of metal coated polymers in low power thermal dissipation application using wire-arc spraying. A circular, structural disk was fabricated from relatively cheap ABS using 3D printing technology [14]. A thin zinc coating was applied on the disk 
surfaces using twin wire-arc spraying, which is a method widely used in industry. A thin film heater was attached to the lower surface of the horizontally mounted disk, and an infrared camera used to measure its temperature distribution as the heater power was increased up to 7.6 W. Heat was conducted radially along the fin and lost from its surface to the ambient air through natural convection and radiation. An analytical heat transfer model was developed, and the model was validated by comparing predicted temperature variations with experimental measurements. Using the analytical solution, two cylindrical, composite heat sinks were designed and their performance was characterized.

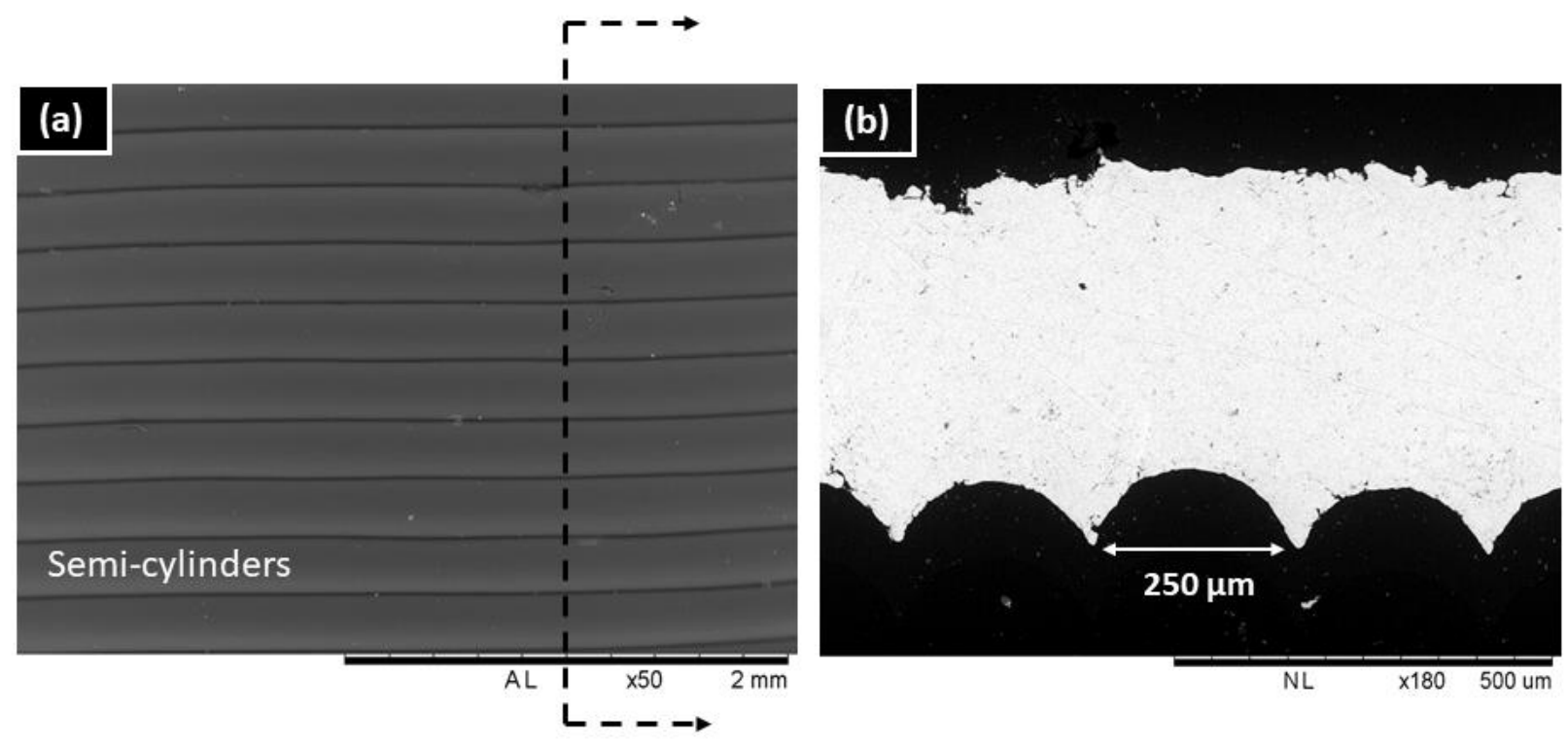

Figure $13 D$ printed ABS surface patterned with semi-cylinders, (a) top viewed semi-cylinders across the surface, and (b) cross-section viewed zinc coatings on plain ABS surface.

\section{Materials and Experimental Procedures}

Thermal spray coating is widely used in industry to apply functional coatings on metal components that can withstand the impact of molten droplets. It is more difficult to coat a polymer substrate that can melt or burn when overheated [15]. Wire-arc spraying was used in this study, in which an electric arc is struck between the tips of two continuously fed wires to melt them. A high-velocity air jet strips the molten metal from the wires and creates a spray of droplets that impact on the substrate. This was used to coat a polymer core with zinc, which has a relatively low melting point $\left(420^{\circ} \mathrm{C}\right)$, did not damage the substrate during coating and adhered well to the substrate. Aluminum is eight times lighter and twice as thermally conductive as zinc, 
making it an excellent material for composite heat sink applications. However, the coating of aluminum on $A B S$ using wire-arc spraying is still a topic requiring further investigation and for the purposes of this study we will focus on utilizing zinc as our coating material.

\subsection{Coating Characterization}

ABS coupons ( $40 \mathrm{~mm} \times 40 \mathrm{~mm} \times 1.5 \mathrm{~mm}$ in size) were made by a 3D printing process that lays down material in layers, leaving patterned semi-cylinders structures on the ABS surfaces, as shown in Fig. 1a. These semi-cylinders, which are approximately $250 \mu \mathrm{m}$ wide as shown in Fig. 1b are aligned with each other across the entire width of the coupons, whose surface roughness is therefore different in the longitudinal and transverse directions. One ABS coupon was left with this surface structure while the other coupons were grit-blasted using aluminum oxide with grit $\# 20$.

During spraying an electric wire arc spray system (ValuArc, Sulzer Metro Inc., Westbury, NY), mounted on a robot arm, was used to melt and spray high purity zinc wires (Catalog\# 1031592, Sulzer Metro Inc., Westbury, NY) onto the coupons and form thin, dense zinc layers on one side. Coupons were coated at three different spray distances (4, 6 and 8 inches) while other arc spraying parameter, listed in Table 1, were kept constant. The robot arm was programmed to make 12 passes while depositing each coating, which gave a coating thickness of approximately $400 \mu \mathrm{m}$.

\begin{tabular}{lc}
\hline & Wire-arc Spray parameters \\
\hline Torch & ValuArc \\
Wire feed rate, $\mathrm{m} / \mathrm{min}$ & 7 \\
Power input, $\mathrm{V}, \mathrm{A}$ & $29.6,200$ \\
Air inlet pressure, psi & 90 \\
Spraying distance, in & $4,6,8$ \\
Spraying passes & 12 \\
\hline
\end{tabular}

Table 1. Wire-arc spray process parameters. 


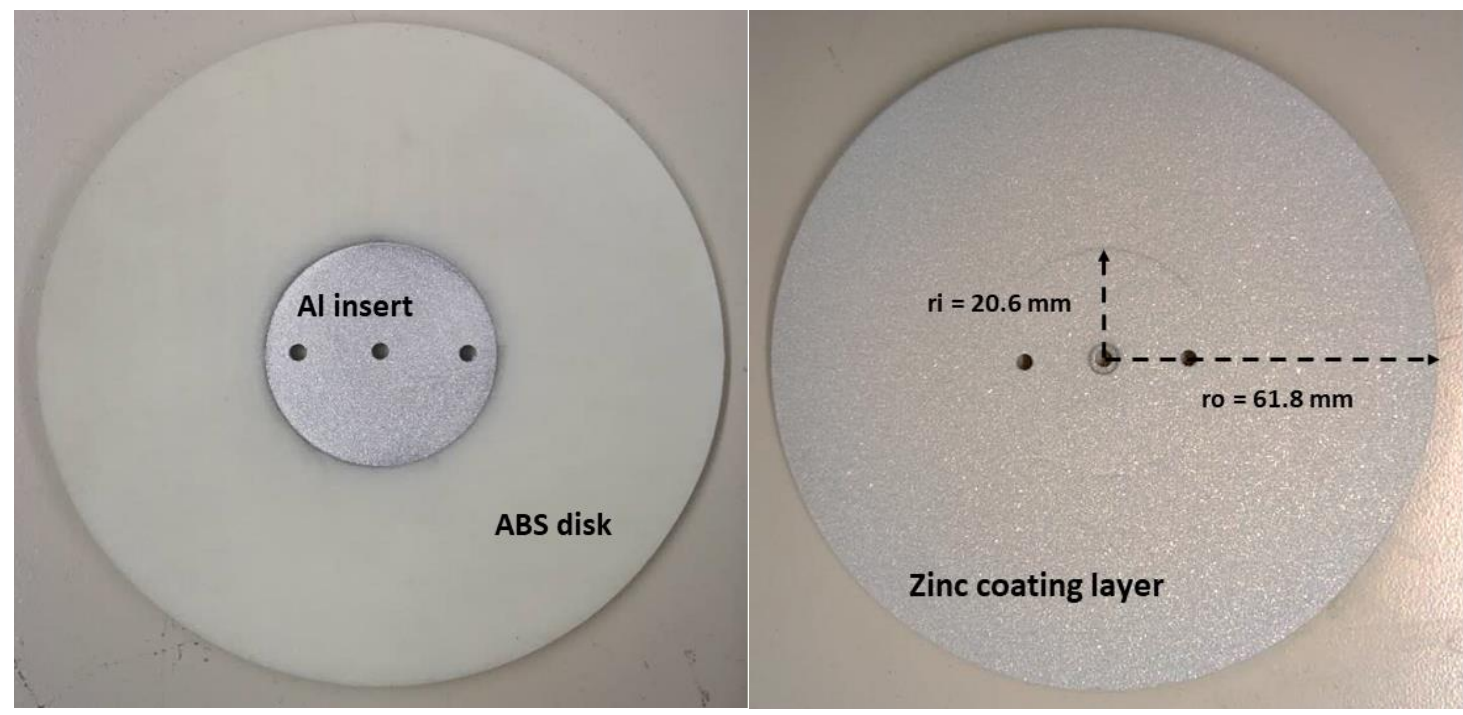

(a)

(b)

Figure 2 Photographs of the annular composite fin, a) before spraying, and b) after spraying.
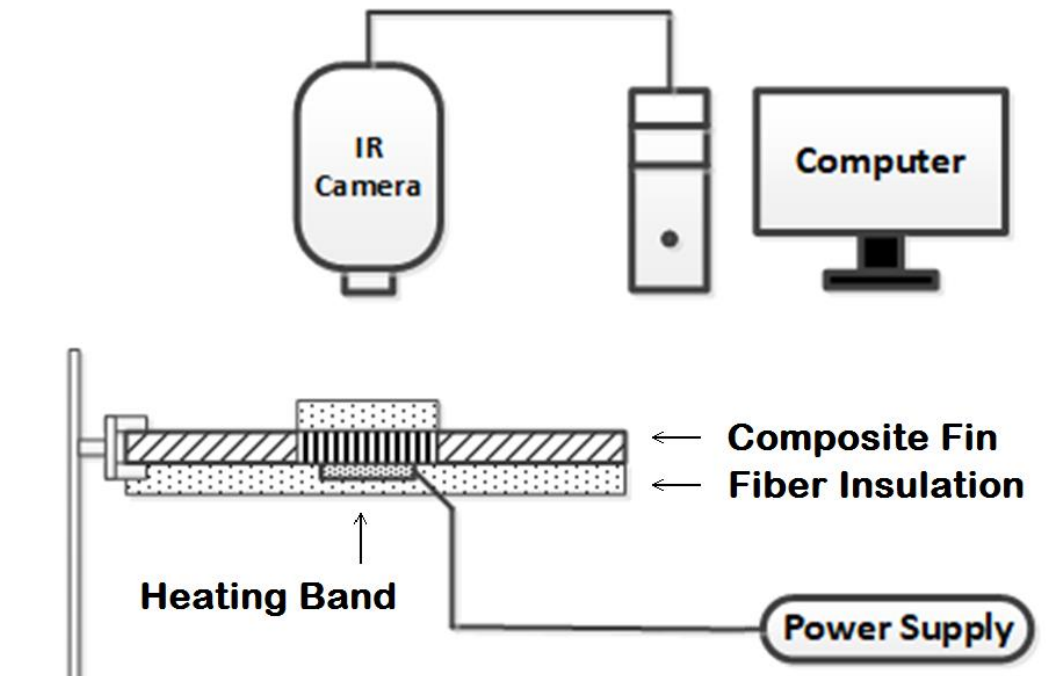

Figure 3 Measuring the temperature distribution of the composite fin using an infra-red camera.

\subsection{Fabrication of Annular composite fin}

An annular composite fin was made by 3D printing a $123.6 \mathrm{~mm}$ diameter ABS disk with $3.2 \mathrm{~mm}$ in thickness. An aluminum disk, $3.2 \mathrm{~mm}$ thick and $41.2 \mathrm{~mm}$ in diameter was inserted into the center of the disk as shown in Fig. 2a and bonded to it using thermally conductive epoxy (DP270, 
$3 M$, St. Paul, USA). The relatively high thermal conductivity of the aluminum $(200 \mathrm{~W} / \mathrm{mK})$ ensured a uniform temperature that was used as a boundary condition in the analytical model. The model assumed radial symmetry and the fin was assumed to be an annulus with an inner radius of 20.6 $\mathrm{mm}$ and an outer radius of $61.8 \mathrm{~mm}$. The surface area of one side of the fin was $106 \mathrm{~cm}^{2}$.

High purity zinc was coated onto the disk using a 4 inch spray distance to create a thin, dense zinc layer on both sides. The average coating thickness can be controlled by varying the number of spraying passes of the robot arm during spraying and in this case coating thickness ( $\mathrm{t}$ ) was kept at $500 \mu \mathrm{m}$. The thermal conductivity of the ABS $\left(k_{1}\right)$ was $0.3 \mathrm{~W} / \mathrm{mK}$ [16] and that of the coated zinc $\left(k_{2}\right)$ was $60(\mathrm{~W} / \mathrm{mK})$ [17]. The final composite fin after coating is shown in Fig. $\mathbf{2 b .}$

\subsection{Heat Transfer Experimental Apparatus}

The annular fin was mounted horizontally as shown in Fig. 3 with its centre heated from below using a flexible, silicone rubber heater, 23 mm square, (35765K126, McMaster Carr, Santa Fe Springs, California, USA) clamped to the aluminum insert using an ABS holder. A $200 \mu \mathrm{m}$ thick thermal graphite pad (Panasonic, $\mathrm{k}=28 \mathrm{~W} / \mathrm{mK}, \mathrm{P} / \mathrm{N}$ : EYG-S1818ZLX2) was placed at the interface between the heater and the fin. The lower surface of the heater and the fin were insulated using fiberglass insulation so that the heat lost from them was negligible. The upper surface of the aluminum insert was also insulated during the experiment. A type-J thermocouple was inserted through a hole at the centre of the fin, touching the graphite pad to measure the junction temperature of the fin and the heater. The temperature variation on the top fin surface was measured using an infra-red camera (ThermaCAM SC 5000, FLIR, USA) pointing downwards to view the entire fin surface which was sprayed with a layer of black graphite (Graphite Lubricant, JIG-A-LOO, Quebec, Canada) to make its thermal emissivity uniform throughout [18]. Type-J thermocouples were used to measure the fin surface temperature at multiple locations and the infrared camera was calibrated by adjusting the surface emissivity setting until the temperatures recorded by the camera matched those measured by thermocouples. A surface emissivity value of $\varepsilon=0.9$ was used in all infrared camera measurements and also to calculate radiation heat losses from the fin. 


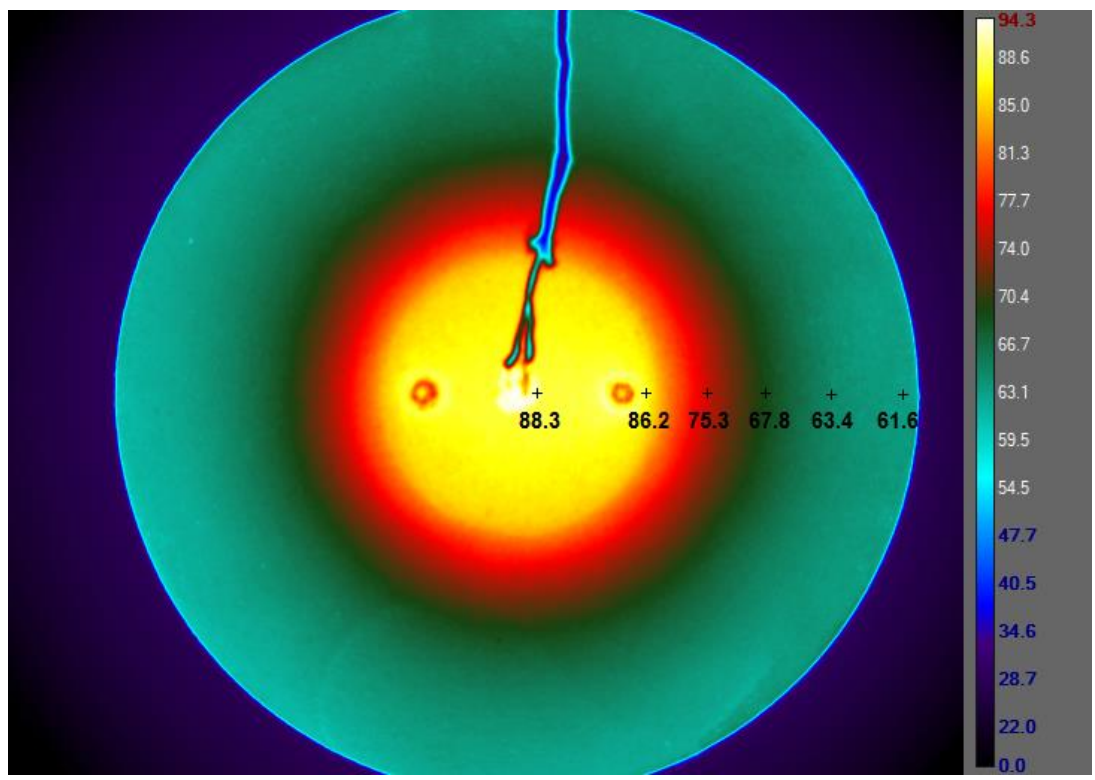

Figure 4 Infra-red image of the top surface of the $123.6 \mathrm{~mm}$ diameter annular fin with $7.6 \mathrm{~W}$ heat input applied to the centre.

The uncertainty associated with the temperature measurement in this study is the combined error of the infra-red camera, Type-J thermocouple and Omega DaqView ${ }^{\mathrm{TM}}$ acquisition system. The camera has a thermal sensitivity of $20 \mathrm{mK}$ at $22^{\circ} \mathrm{C}$ and an accuracy of $\pm 1 \%$ for the temperature range of 5 to $300 \stackrel{\circ}{ } \mathrm{C}$. The camera is calibrated using the thermocouple adhered to the substrate. The Type-J thermocouple used in the study has the accuracy of $\pm 1.1 \stackrel{\circ}{ }$, and the zero-order uncertainty associated with the Personal DaqView-TM for Type-J thermocouples is $\pm 0.0005^{\circ} \mathrm{C}$. Therefore, for instance, the nominal temperature of $88.3^{\circ} \mathrm{C}$ indicated in Fig. 4 , has an overall uncertainty of $\pm 1.4 \stackrel{\circ}{\circ}$. The procedure of computing the uncertainty follows the rootsum-squares (RSS) method that is described by Figliola [19].

The power supplied to the heater was varied from $1.3 \mathrm{~W}$ to 7.6 W. At each power setting the annular fin was allowed to come to steady state, which took approximately 20 min, and the temperature on the top fin surface recorded. Fig. 4 shows an infra-red image of the temperature variation on the top fin surface (without fiber insulation on the insert) when the applied power was $7.6 \mathrm{~W}$. The temperature of the coating above the aluminum insert was quite uniform, with the difference between its centre and edge being around $2{ }^{\circ} \mathrm{C}$. The temperature field in the fin was radially symmetric and the isotherms were circular. In the analytical model, it was assumed 
that the fin was an annulus, with the temperature at the inner radius constant and equal to the averaged temperature that measured at the centre and the edge of the insert.

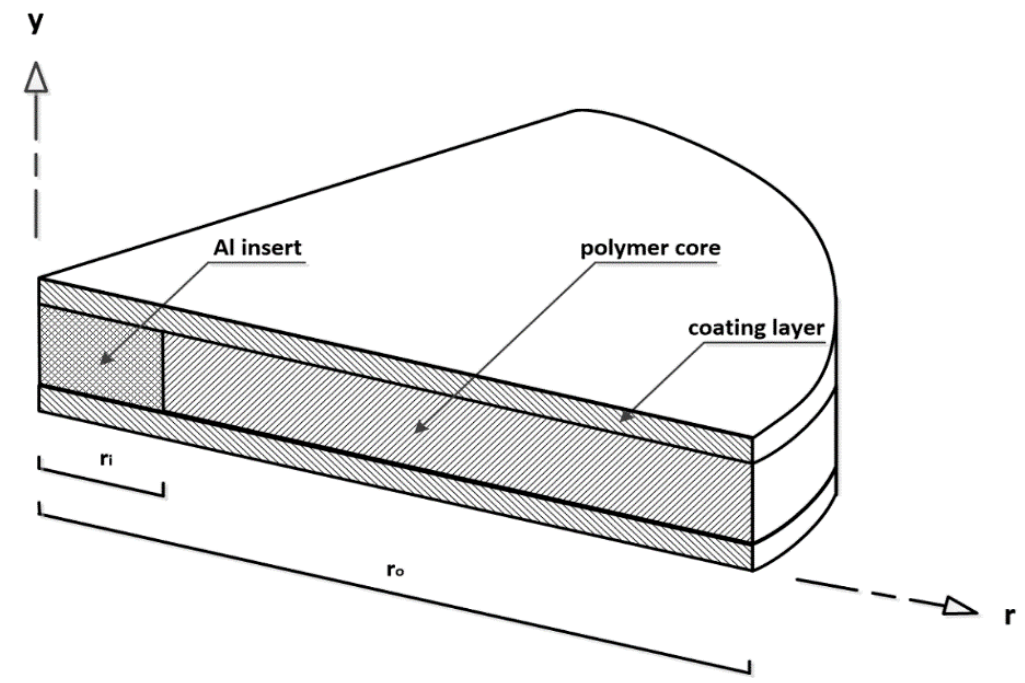

Figure 5 Schematic of a quarter of the composite annular fin.

\section{Heat Transfer Model}

Most studies on composite fins have assumed the fins to be rectangular. There is, in addition, a significant body of literature on heat conduction in annular fins, with both one-dimensional and two-dimensional models proposed [20], [21], [22], [23] and [24]. The 'thermal length', which combines the physical properties and dimensions of the fin has been used to characterize fin designs. Results from models show that fin efficiency decreases as thermal length increases, and that fins with reduced thickness have lower efficiencies. In this study, the composite fin was circular with a rectangular cross-section as seen in Fig. $\mathbf{5}$ which is a schematic that shows a quarter of the fin. The annular composite fin was constructed as a sandwich structure with a polymer core with thickness $H$, an outer radius $r_{o}$, and inner radius $r_{i}$. 
h, $\mathbf{T}_{\text {air }}$

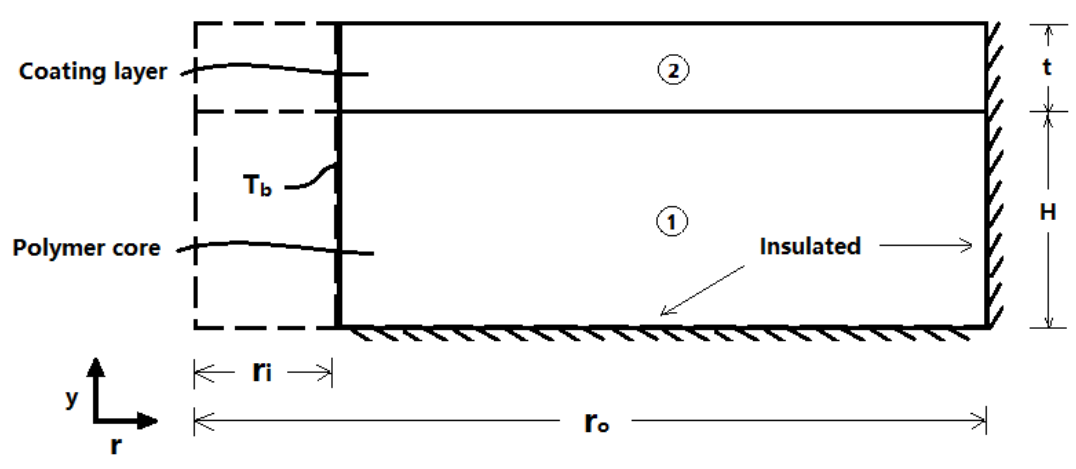

Figure 6 Analytical heat conduction model of the composite fin consisting of two domains.

The geometry can be simplified for purposes of modelling as shown in Fig. 6 that displays a cross-section through the fin. The system was assumed to be a rectangular region of width $H$ the bottom of which is insulated while the zinc coating has thickness $t$ and is in perfect thermal contact with the polymer. The thermal conductivity of the polymer core and the metallic coating layers are $k_{1}$ and $k_{2}$, respectively; At $r=r_{i}$ the temperature is uniform $\left(T=T_{b}\right)$ while the outer surface $r=r_{o}$ is insulated. Heat is lost from the upper surface of the coating by convection and radiation to the surrounding air, assumed to be at $20^{\circ} \mathrm{C}$. The natural convection heat transfer coefficient $h$ is estimated using the experimental correlation [25] for an upward facing horizontal plate,

$$
N u=0.54 R a^{1 / 4}, 10^{4}<R a<10^{7}
$$

$R a$ is the Rayleigh number and $\mathrm{Nu}$ is the Nusselt number defined as

$$
\begin{gathered}
R a=\frac{g \beta\left(T_{b}-T_{a i r}\right) \delta^{3}}{v^{2}} \operatorname{Pr} \\
N u=\frac{h \delta}{k}
\end{gathered}
$$

Where $\operatorname{Pr}$ is Prandtl number, $\delta$ the characteristic length of the semi disk, $\beta$ the coefficient of volume expansion, $v$ the kinematic viscosity of the fluid, and $k$ the thermal conductivity of the fin. Thermal properties were estimated at an average temperature, $\frac{T_{b}+T_{a i r}}{2}$. The transverse thermal 
resistance of the coating layer in the $y$-direction $\left(t / k_{2}\right)$, is several orders of magnitude smaller than that in the polymer core $\left(H / k_{1}\right)$, and the calculated Biot number, in which $\mathrm{Bi}^{-1} 10^{-4}$ in Section 4 , indicates that temperature gradient in the coating is dominated in the radial direction [26]. The analytical model for heat transfer in the fin therefore assumes one-dimensional heat conduction in the coating and two-dimensional heat conduction in the polymer core.

Heat conduction in the two-dimensional polymer core is governed by the following partial differential equation,

$$
\frac{\partial^{2} T_{1}}{\partial r^{2}}+\frac{1}{r} \frac{\partial T_{1}}{\partial r}+\frac{\partial^{2} T_{1}}{\partial y^{2}}=0
$$

Since heat transfer in the coating is assumed to be one-dimensional, with a temperature gradient only in the radial direction [26], an energy balance gives

$$
k_{2} t\left(\frac{\partial^{2} T_{2}}{\partial r^{2}}+\frac{1}{r} \frac{\partial T_{2}}{\partial r}\right)-h_{e}\left(T_{2}-T_{a i r}\right)=\left.k_{1} \frac{\partial T_{1}}{\partial y}\right|_{y=H}
$$

Where $h_{e}=h+4 T_{\text {air }}{ }^{3} \varepsilon \sigma$ is an effective heat transfer coefficient that combines convection and radiation effects. The first term on the left-hand side of equation (5) represents heat conduction and the second a combination of natural convection and radiation.

The fin parameter $M$ is defined,

$$
M=\sqrt{\frac{h_{e}}{k_{1} H+k_{2} t}}
$$

The temperature variation on the coating surface can be obtained by solving equations (4) and (5) along with the boundary conditions [4] [26] giving

$$
T_{2}(r)=\cos (M H) \frac{I_{o}(M r) K_{1}\left(M r_{o}\right)+I_{1}\left(M r_{o}\right) K_{o}(M r)}{I_{o}\left(M r_{i}\right) K_{1}\left(M r_{o}\right)+I_{1}\left(M r_{o}\right) K_{o}\left(M r_{i}\right)}\left(T_{b}-T_{a i r}\right)+T_{a i r}
$$


Where $I_{n}(x)$ and $K_{n}(x)$ are the solutions to the modified Bessel differential function of the first and second kinds[27] [28]. The heat conduction through the fin can be derived from,

$$
Q=\left.k A \frac{d T_{2}}{d r}\right|_{r=r_{i}}
$$

Where $A$ is the fin cross-section area at $r=r_{i}$. Evaluating equation (8) gives

$$
Q=\cos (M H) M \frac{I_{1}\left(M r_{o}\right) K_{1}\left(M r_{i}\right)-I_{1}\left(M r_{i}\right) K_{1}\left(M r_{o}\right)}{I_{1}\left(M r_{o}\right) K_{0}\left(M r_{i}\right)+I_{0}\left(M r_{i}\right) K_{1}\left(M r_{o}\right)}\left(T_{b}-T_{a i r}\right) \cdot 2 \pi r_{i}\left(k_{1} H+k_{2} t\right)
$$

The fin efficiency can be defined as,

$$
\eta_{\text {fin }}=\frac{Q}{Q_{\max }}
$$

Where $Q_{\max }$ is the maximum possible heat transfer from a fin whose entire surface is at the base temperature. Using Eqn 9,

$$
\eta_{f i n}=2 \cdot \cos (M H) \frac{1}{M L} \frac{1}{\left(\frac{r_{o}}{r_{i}}+1\right)} \frac{I_{1}\left(M r_{o}\right) K_{1}\left(M r_{i}\right)-I_{1}\left(M r_{i}\right) K_{1}\left(M r_{o}\right)}{I_{1}\left(M r_{o}\right) K_{0}\left(M r_{i}\right)+I_{0}\left(M r_{i}\right) K_{1}\left(M r_{o}\right)}
$$

Given the characteristic length $\left(L=r_{i}-r_{o}\right)$ and radius ratio $\left(\frac{r_{o}}{r_{i}}\right)$, both $r_{i}$ and $r_{o}$ can be determined, so the composite fin efficiency is governed by two nondimensional parameters, the 'thermal length' of the fin $(M L)[6]$ and the radius ratio $\left(\frac{r_{o}}{r_{i}}\right)$.

\section{Results and discussions}

\subsection{Porosity and adhesion strength}

The roughness of the ABS surfaces, defined as the vertical deviations of the measured surface from an ideal flat plane, was determined using a surfometer (Precision Devices, INC., Milan, Michigan). Five measurements were made at different locations on each surface before spraying, and the average $R a$ value of each sample and its standard deviation are shown in Table 2 . The 
roughness of the plain $\mathrm{ABS}$ surface, $\mathrm{UB}\left(4^{\prime \prime}\right)$, was measured in both longitudinal $\left(R_{a}=0.3 \mu \mathrm{m}\right)$ and transverse directions $\left(R_{a}=4.3 \mu \mathrm{m}\right)$, and the large difference between the two was a result of the semi-cylindrical patterns on the surface while the three sandblasted coupons, $B\left(4^{\prime \prime}\right), B\left(6^{\prime \prime}\right)$ and $B\left(8^{\prime \prime}\right)$, have very similar surface roughness to each other and in both directions. The microstructure of coating layers and bonding interfaces were examined using a scanning electron microscope (S-570, Hitachi High-Technology Canada Incorporated, Toronto, ON). Images of the samples captured at magnifications of 100 and 800 were imported into Image for analysis, and the coating thickness and porosity were measured. The micrographs are 8-bit images that have 256 colors. For analysis, a measurement scale was set using the reference length in the SEM images, and at the magnification of 800 one pixel was $0.12 \mu \mathrm{m}$. The threshold of the images was set to IsoData with B\&W colors. For coating sample UB (4"), the grey level distribution is $40.55 \%$ in a threshold range of 0 to 128 . The coating thickness and porosity are averaged of six measurements (three measurements per image) and listed in Table 2. In no surface treatment sample UB(4"), the coating thickness refers to the distance between the peak of the semi-cylinder and the top of the coatings. The adhesion strengths of the metal-polymer coatings were determined by a pull-off test based on ASTM D4541 using $20 \mathrm{~mm}$ Dollies, and the results are presented in Table 2. The Dollies were adhered to the metal coating using a $2 \mathrm{~K}$-epoxy adhesive (\#19770, Devcon, Davers, USA) that was cured overnight. Pull-off testing was conducted using PosiTest AT-M manual pull off adhesion tester (PosiTest ATM20, DeFelsko Corp. Ogdensburg, NY, USA).

\begin{tabular}{lcccc}
\hline Sample & $\begin{array}{c}\text { Surface Roughness } \\
\text { (standard deviation) } \\
\boldsymbol{\mu m}\end{array}$ & $\begin{array}{c}\text { Thickness } \\
\boldsymbol{\mu m}\end{array}$ & $\begin{array}{c}\text { Porosity } \\
\%\end{array}$ & $\begin{array}{c}\text { Adhesion strength } \\
\mathrm{MPa}\end{array}$ \\
\hline 1. UB (4") & $0.3(0.03), 4.3(0.05)$ & 430 & $2.5 \pm 0.4$ & $0.64 \pm 0.12$ \\
2. B (4") & $2.4(0.50)$ & 420 & $1.4 \pm 0.6$ & $2.62 \pm 0.24$ \\
3. B (6") & $2.5(0.31)$ & 410 & $2.4 \pm 0.3$ & $1.18 \pm 0.02$ \\
4. B (8") & $2.2(0.22)$ & 380 & $1.3 \pm 0.8$ & $1.17 \pm 0.05$ \\
\hline
\end{tabular}

Table 2. Specifications of four zinc coated ABS coupons. 


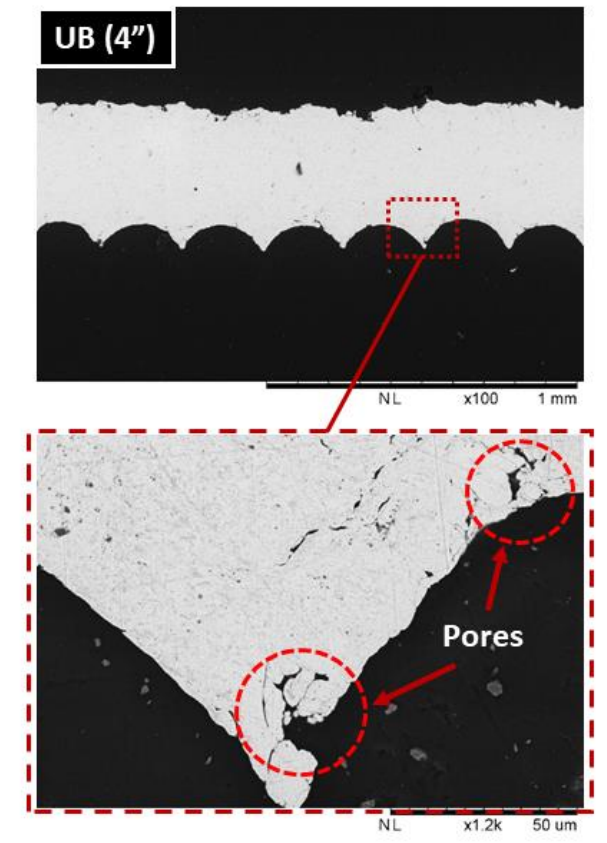

(a)

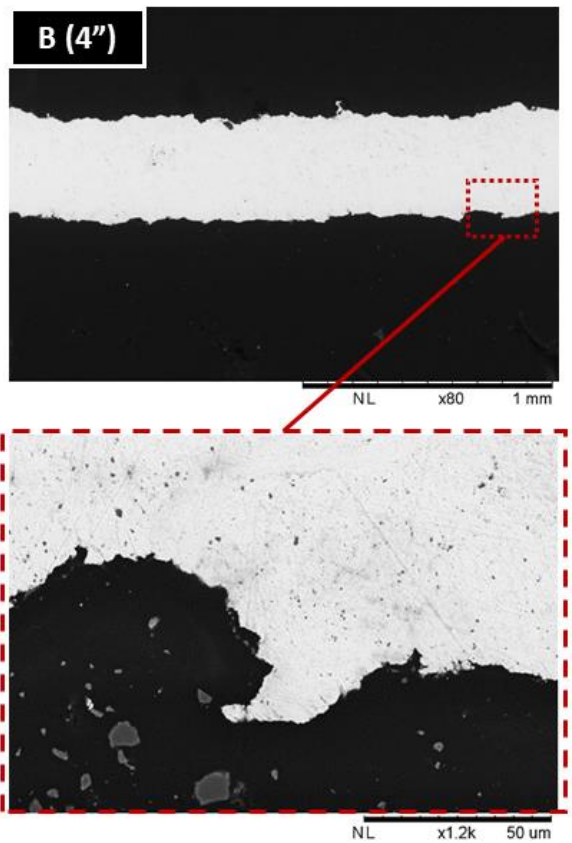

(b)

Figure 7 Mechanical bond microstructure of two sprayed ABS coupons prepared in different surface roughness, a) plain ABS and b) grit blasted,

When the spray distance was increased from 4 to 8 inches the porosity did not vary significantly but coating thickness decreased slightly while adhesion strength was significantly reduced. During wire-arc spraying the carrier gas stream creates a conical spray of molten particles that is propelled towards the ABS substrates. In the test, the porosity shows consistency in the coating samples, which might because in the current setting of the spraying the zinc particles are gaining sufficient thermal energy and the loss over the flying distance can be negligible from 4 to 8 inches. However, a higher spray distance increases the footprint of the spray and therefore the flux of particles on a given area is reduced and therefore the coating thickness. Also, increasing spray distance reduces droplet impact velocity [29] and gives a lower bonding strength.

The coating sprayed at 4 inches on the grit-blasted surface had the highest adhesion strength of $2.62 \mathrm{MPa}$, significantly higher than that on the untreated surface where the adhesion strength was only 0.64 MPa. Fig. 7 has SEM images of cross-sections showing the interface between the coating and substrates. Grit-blasting removed the cylindrical patterns on the printed ABS 
coupons so that the treated coupon (Fig. 7b) has a flatter surface than the coupon that received no surface treatment (Fig. 7a). The sprayed particles fill the valleys between the semi-cylinder structures on the untreated surface but pores are formed in the valleys because of shadowing effects due to the curved surface. Grit-blasting created a flat but rough surface so that impacting molten metal particles fill crevices in the surface and after solidification create mechanical interlocking as shown in Fig.7b. Grit blasting therefore enhances adhesion strength.

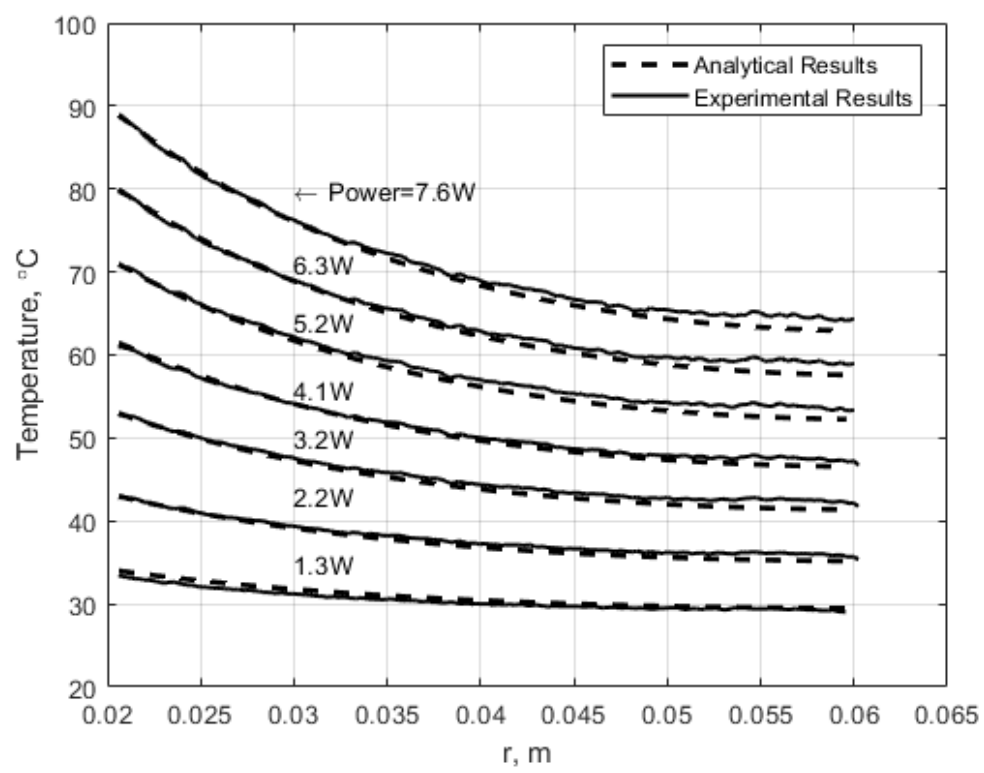

Figure 8 Measured and calculated radial temperature variations of the composite annular fin at various power inputs. The ambient temperature is $20^{\circ} \mathrm{C}$.

\subsection{Surface temperature measurement and prediction}

Fig. 8 shows both measured and calculated radial temperature variations on the top surface of the fin for seven values of the heater power. The experimental radial temperature profile is determined by setting a given input power to the heater, and recording the temperature distribution using the IR camera and local thermocouple temperature measurements. The temperature is maximum closest to the center of the fin where the heater is located and decreases radially. Increasing the heater power raises the temperature. The calculated radial temperature distribution is a function of the base temperature, as seen in Eqn 7, and is independent of the power input. The predictions agree well with the experimental 
measurements. At higher radius the measured temperature is slightly higher $\left(<2{ }^{\circ} \mathrm{C}\right)$ than the prediction, but the difference is of the same magnitude as the associated experimental uncertainty of the temperature measurement. In the analytical model, the natural convection coefficients are $5.9,6.7,7.4,7.8,8.2,8.5$ and $8.7 \mathrm{~W} / \mathrm{m}^{2} \mathrm{~K}$ at base temperatures of $35,43,53,61$, 71,80 and $89{ }^{\circ} \mathrm{C}$, respectively, and the radiation heat transfer coefficient, $4 T_{\text {air }}{ }^{3} \varepsilon \sigma$, is $5.1 \mathrm{~W} / \mathrm{m}^{2}$ K. Radiation therefore plays a significant role in heat transfer from the fin.

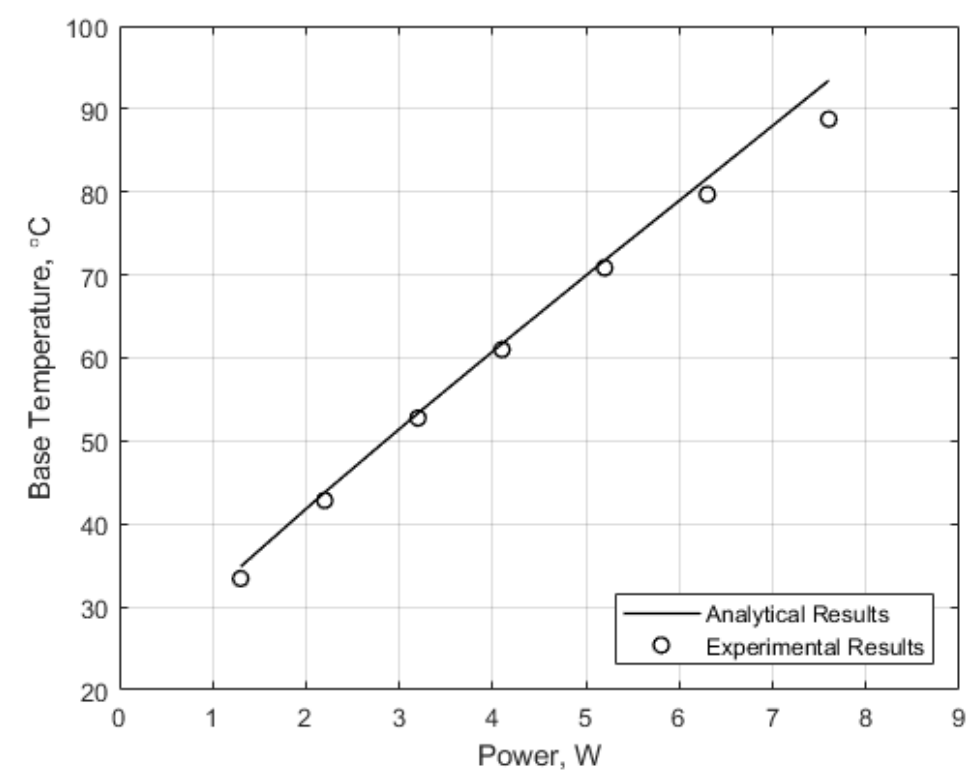

Figure 9 Measured and calculated base temperature of the composite annular fin at varying power input.

Fig. 9 shows both measured and predicted variation of the base temperature of the fin, measured at the interface between the aluminum insert and the polymer fin, with the applied heater power. In this case, for both the experimental and analytical, the base temperature is a function of the power input, as described in Eqn 9. The calculated base temperature agrees well with the measured base temperature, and both increase with heater power. The thermal resistance of natural convection and radiation is the reciprocal of the effective heat transfer coefficient,

$$
R=\frac{1}{h_{e}}
$$


Where $h_{e}=h+4 T_{\text {air }}{ }^{3} \varepsilon \sigma$ and is a function of the Rayleigh number $R a$ and the ambient temperature. $R a$ depends on the fin temperature and increases with base temperature. The natural convection coefficient increases with the power input, so the overall thermal resistance decreases with increasing heater power.

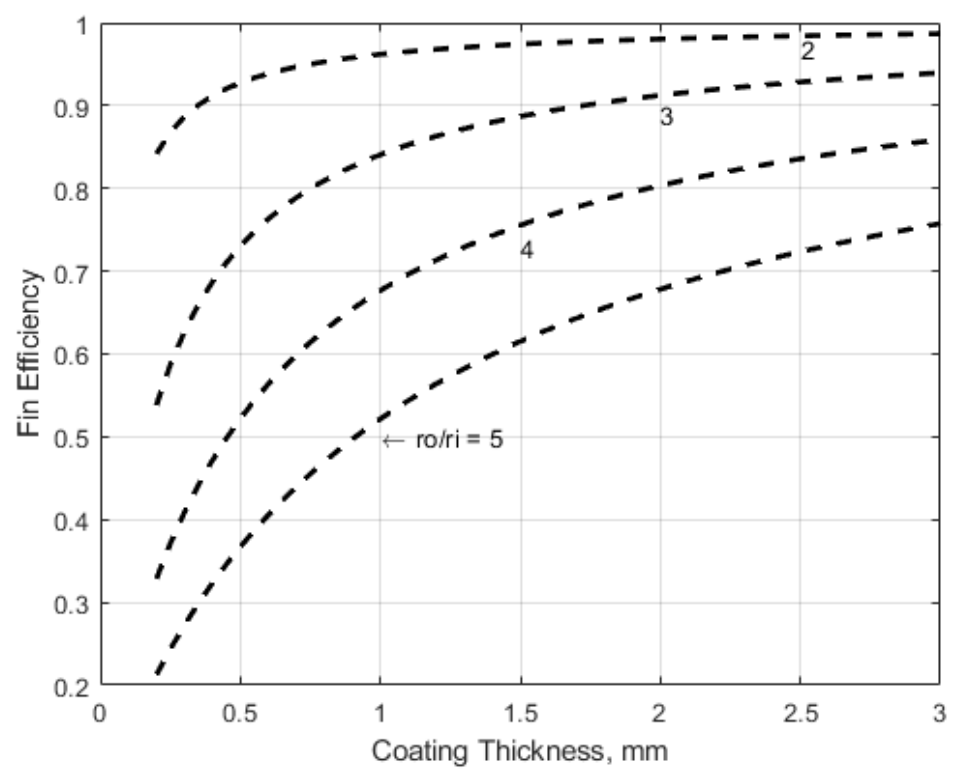

Figure 10 Change in the efficiency of the composite annular fin calculated from Equation 11 with varying coating thickness and $r_{0} / r_{i}$ ratios.

The calculated variation in fin efficiency of annular composite (polymer/zinc) fins with coating thickness at four different $r_{0} / r_{i}$ ratios is presented in Fig. 10. Polymer core thickness, the inner fin radius $r_{i}$ and all thermal properties were assumed to be the same as those in our experiment. Fin efficiency increases with coating thickness in all cases because, as seen in Eqn 11, fin efficiency is a function of the fin parameter $M$ which decreases as coating thickness increases. For the annular fin that was tested in experiments, $r_{0} / r_{i}=3$ and the coating thickness was $0.5 \mathrm{~mm}$, giving a fin efficiency of approximately $73 \%$. Fin efficiency can be improved by reducing the fin radius since heat transfer decreases with distance from the center of the fin, so reducing $r_{0} / r_{i}$ or increasing coating thickness would improve efficiency. The coating thickness has more influence on the efficiency of fins with a larger $r_{o} / r_{i}$ ratio. For instance, the efficiency is increased by $30 \%$ and $12 \%$ as the coating thickness increased from $0.25 \mathrm{~mm}$ to $1.00 \mathrm{~mm}$ at $r_{0} / r_{i}$ of 5 and 2 , respectively. As 
the coating thickness increases it reaches a thickness where the thermal resistance through the coating matches that of the thermal resistance of heat transfer to the surrounding ambient conditions. After this point, any increase in coating thickness results in diminishing return in terms of thermal dissipation and thus fin efficiency. This is denoted in Fig. 10 by the asymptotic trend of all curves as the coating thickness is increased.

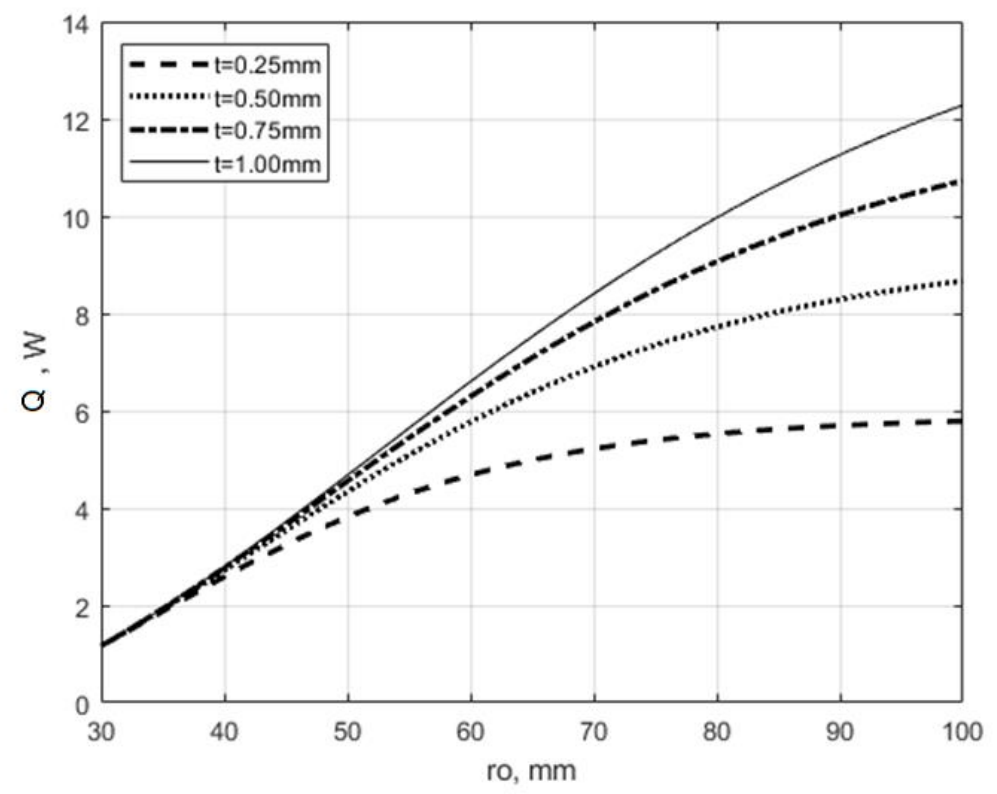

Figure 11 Heat dissipation of the fins as a function of outer fin radius at different coating thickness. The inner radius $r_{i}=20.6 \mathrm{~mm}$ and base temperature $T_{b}=80^{\circ} \mathrm{C}$.

The total power dissipated by a fin depends on both the fin radius and the coating thickness. Fig. 11 shows the change in total heat dissipation, calculated from Eqn. 9, from the top surface of the circular fin if the outer radius and coating thickness of the fin used in experiments (with $r_{i}$ $=20.6 \mathrm{~mm}$ and $T_{b}=80^{\circ} \mathrm{C}$ ) are varied. The annular fin tested had a coating thickness $t=0.5 \mathrm{~mm}$ and outer radius $r_{o}=61.8 \mathrm{~mm}$, and from Fig. 11 it dissipated approximately $6.0 \mathrm{~W}$ of energy. For a given radius, the heat dissipated increased with coating thickness, but this effect became less as the thickness became larger. For a fin with a radius of $50 \mathrm{~mm}$, there was little difference in the heat lost from a 0.75 or $1.00 \mathrm{~mm}$ thick coating. Once the metal coating is sufficiently thick its thermal resistance becomes much smaller than that due to natural convection in the surrounding 
air. Since the two are in series the total thermal resistance of the heat sink is dominated by the resistance of the air and further increasing coating thickness offers little benefit.

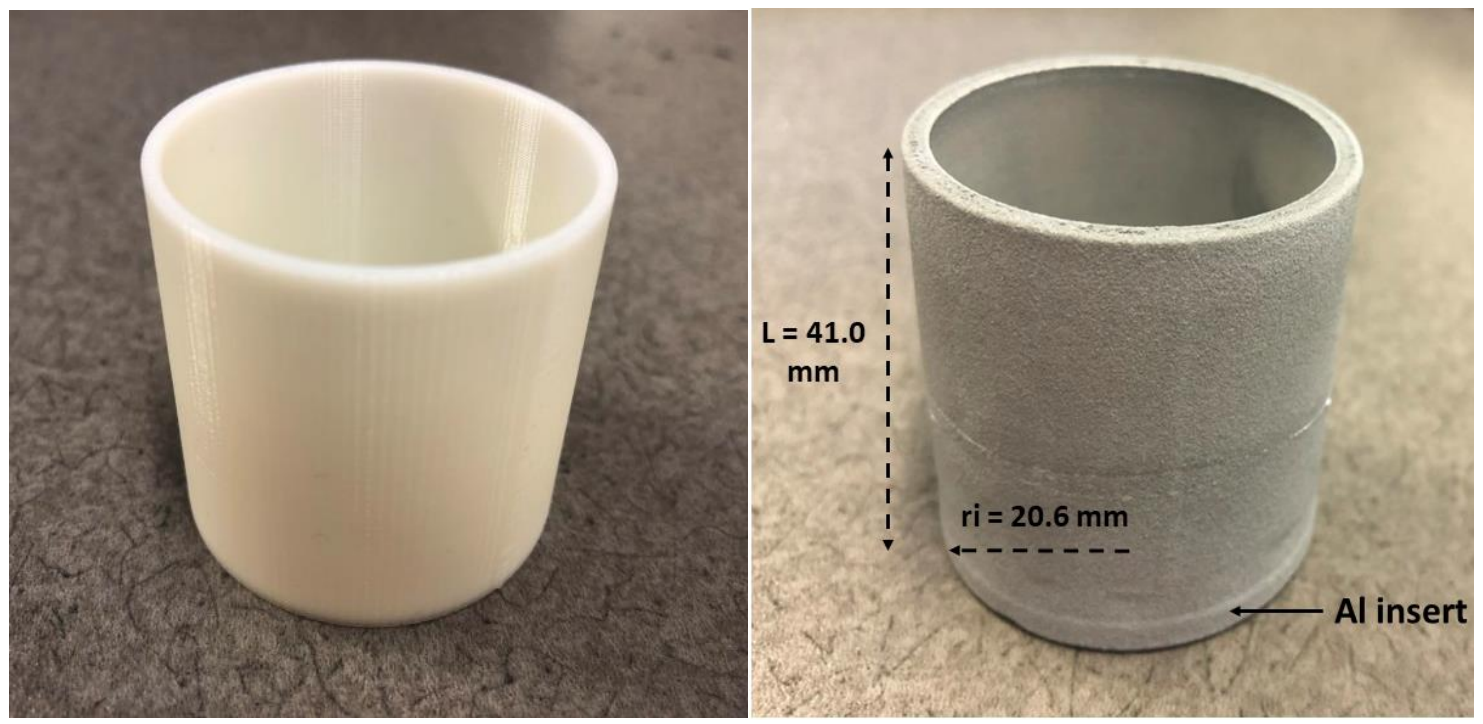

(a)

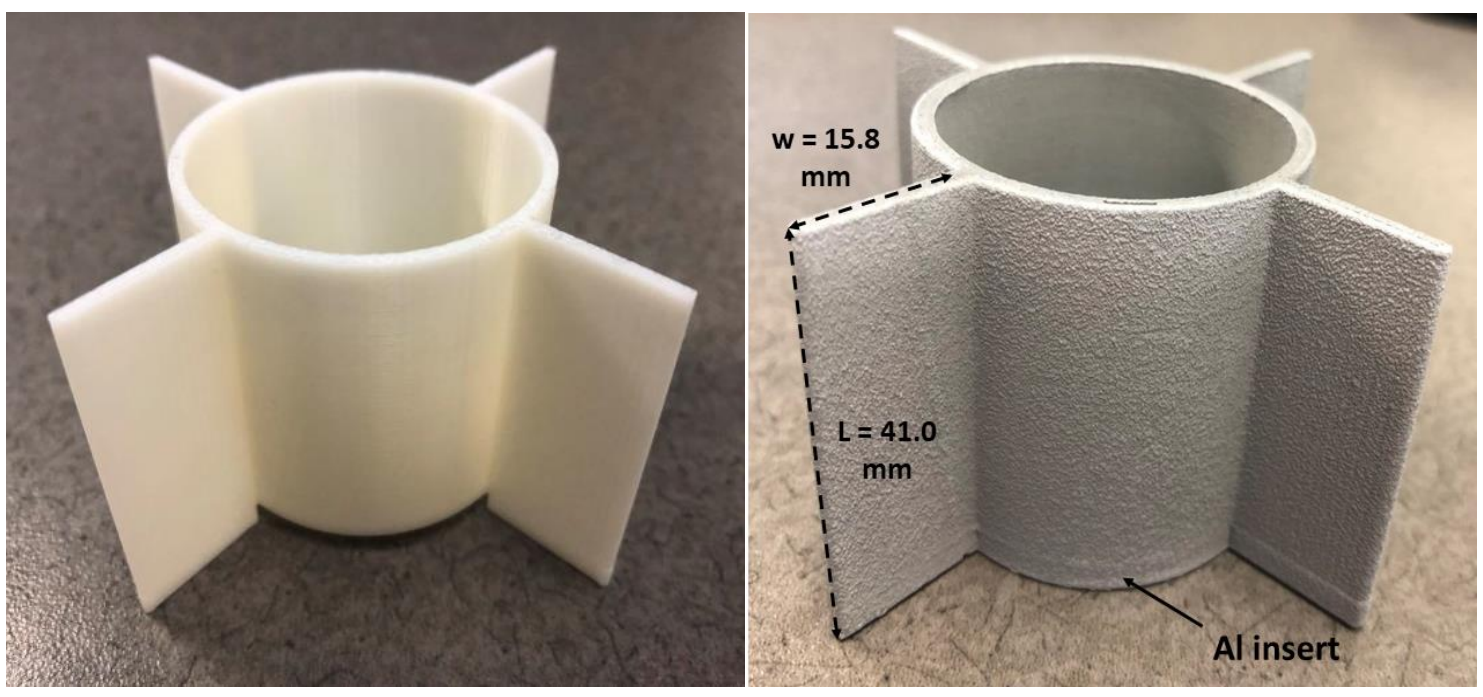

(b)

Figure 12 Photographs of a) cylindrical and b) finned heat sinks, before and after spraying.

\subsection{Composite heat sink designs}

Two cylindrical heat sinks were designed to have the same radius ratio as the composite annular fin. The first heat sink, cylinder (see Fig. 12a), has a total effective heat transfer area of $53 \mathrm{~cm}^{2}$ (half that of the annular fin), and the second, cylinder with vertically projecting fins (see Fig. 12 
b), was $106 \mathrm{~cm}^{2}$ (the same as the annular fin). They were fabricated in a similar manner to that of the annular composite fin, by spraying zinc coatings onto cores of acrylonitrile butadiene styrene (ABS) made by 3D printing. The cylinder has an outer radius of $20.6 \mathrm{~mm}$, height of 41.0 $\mathrm{mm}$, and a wall thickness of $1.5 \mathrm{~mm}$ (see Fig. 12a), while the other consisted of a cylinder with the same dimension from which extended four vertical rectangular fins at $90^{\circ}$, each $15.8 \mathrm{~mm}$ wide (Fig. 12b). An aluminum disk with a radius of $20.6 \mathrm{~mm}$ and a thickness of $3.2 \mathrm{~mm}$ was bonded using thermally conductive epoxy to the bottom of each cylinder. Zinc coatings were sprayed on the outer surface of the polymer cores and the aluminum base. The insides of the cylinders were not coated as it was difficult to control the coating thickness when spraying at an angle. The average coating thickness, determined by measuring the weight of metal deposited and dividing it by the density of zinc and the surface area coated, was $640 \mu \mathrm{m}$ for the cylindrical heat sink and $530 \mu \mathrm{m}$ for the finned heat sink.

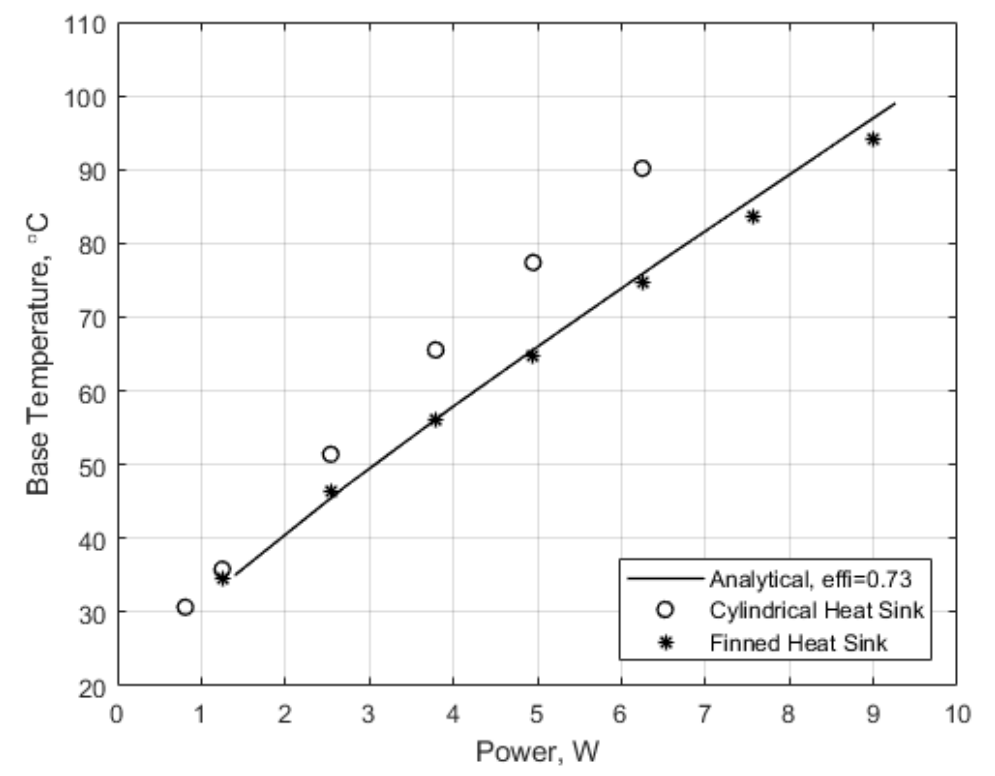

Figure 13 Change in base temperature of the cylindrical and finned heat sinks with heater power, compared to the analytical prediction from Equations 10 and 11.

The cylindrical and finned heat sinks were tested by attaching a heater pad to their bases, varying the power supplied to it, and measuring the base temperature. The test results are shown by the data points in Fig. 13 along with a line showing the calculated heat loss from the analytical 
model. The heat lost from a heat sink depends on the total surface area available and the length of the conduction path from the heater to the surface of the heat sink. Therefore, even though the model is for a disk and the heat sinks are cylindrical, the heat loss will be similar as long as these two parameters are the same. The results shown in Fig. $\mathbf{1 3}$ confirm that predicted values are close to those of the finned heat sink, whose surface area was the same as that of the annular fin; however, the cylindrical fin, which had half the surface area, had significantly higher base temperatures for the same applied power. Therefore, the analytical model of the composite annular fin can be applied to and used as a guide to design cylindrical and finned heat sinks.

\section{Conclusions}

Wire-arc spraying was used to fabricate three polymer-metal composite heat sinks, one in the shape of a disk, the second a cylinder, and the third a cylinder with radially extending fins. A Zinc coatings (0.4-0.7 mm thick) were applied on both untreated and grit-blasted ABS substrates and the adhesion strength of the coating was evaluated using a pull-off test. Adhesion strength depended on both surface roughness and spray stand-off distance and the maximum adhesion strength achieved was $2.6 \mathrm{MPa}$. The heat sinks were tested by applying a heat flux to their base and varying the heater power while measuring the base temperature and radial temperature distribution. An analytical model of heat conduction through the annular fins was developed, and the calculated temperature distributions agree well with the measurements. In this model, the fin efficiency is governed by two dimensionless parameters: the thermal length $(M L)$ and the

radius ratio $\left(\frac{r_{o}}{r_{i}}\right)$ of the fins. This model for an annular fin could also predict heat loss from cylindrical fins that with the same surface area as that of the disk. A coating thickness of 0.5 to 1 $\mathrm{mm}$ was sufficient to make the conduction resistance much smaller than the resistance to convection and radiation from the surface for the cases tested. Depositing more metal on the heat sink surface would not enhance heat transfer significantly. 


\section{Reference}

1. Narukawa, Y., et al., White light emitting diodes with super-high luminous efficacy. Journal of Physics D: Applied Physics, 2010. 43(35): p. 354002.

2. Kim, L., et al., Thermal analysis of LED array system with heat pipe. Thermochimica Acta, 2007. 455(1-2): p. 21-25.

3. Yang, S.C., et al., A Study of Heat Transfer Characteristics of LED Heat Sink and Graphite Heat Sink Process Technology Development. Applied Mechanics and Materials, 2013. 284287: p. 819-823.

4. Feng, C., Investigation of thermal performance of heat spreaders fabricated by thermal spray technology. Ph.D. Thesis, 2019.

5. Mamunya, Y.P., et al., Electrical and thermal conductivity of polymers filled with metal powders. European Polymer Journal, 2002. 38: p. 1887-1897.

6. Wang, R.-T. and J.-C. Wang, Analyzing the structural designs and thermal performance of nonmetal lighting devices of LED bulbs. International Journal of Heat and Mass Transfer, 2016. 99: p. 750-761.

7. R.Mohan; and P.Govindarajan; , Thermal analysis of CPU with composite pin fin heat sinks International Journal of Engineering Science and Technology, 2010. 2(9): p. 4051-4062.

8. Arshad, A., et al., Thermal performance of phase change material (PCM) based pin-finned heat sinks for electronics devices: Effect of pin thickness and PCM volume fraction. Applied Thermal Engineering, 2017. 112: p. 143-155.

9. Stark, J.R., C.D. Sevart, and T.L. Bergman, Experimentally validated analytical expressions for the thermal resistance of a novel composite fin-foam annular array. Applied Thermal Engineering, 2018. 131: p. 260-269.

10. Barker, J.J., The Efficiency of Composite Fins. Nuclear Science and Engineering, 2017. 3(3): p. 300-312.

11. Lindsay, J.H., Coatings and coating processes for metals. ASM International, Member/Customer Service Center, Materials Park, OH 44073-0002, USA, 1998. 353, 1998.

12. Che, H., et al., Metallization of Various Polymers by Cold Spray. Journal of Thermal Spray Technology, 2017. 27(1-2): p. 169-178. 
13. Che, H., P. Vo, and S. Yue, Investigation of Cold Spray on Polymers by Single Particle Impact Experiments. Journal of Thermal Spray Technology, 2018. 28(1-2): p. 135-143.

14. Haertel, J.H.K. and G.F. Nellis, A fully developed flow thermofluid model for topology optimization of 3D-printed air-cooled heat exchangers. Applied Thermal Engineering, 2017. 119: p. 10-24.

15. Gonzalez, R., et al., A Review of Thermal Spray Metallization of Polymer-Based Structures. Journal of Thermal Spray Technology, 2016. 25(5): p. 897-919.

16. Kumlutas;, D., I.s.H. Tavman; and M.T. Coban, Thermal conductivity of particle filled polyethylene composite materials. Composites Science and Technology 2003. 63: p. 113117.

17. Porter, F.C., Zinc handbook: properties, processing, and use in design. 1991: Crc Press.

18. Vollmer, M. and M. Klaus-Peter, Infrared thermal imaging: fundamentals, research and applications. 2017: John Wiley \& Sons.

19. Figliola, R.S. and D.E. Beasley, Theory and Design for Mechanical Measurements. USA. Wiley, 2011(5th ed.).

20. Sharqawy, M.H. and S.M. Zubair, Efficiency and optimization of an annular fin with combined heat and mass transfer - An analytical solution. International Journal of Refrigeration, 2007. 30(5): p. 751-757.

21. Ullmann, A. and H. Kalman, Efficiency and optimized dimensions of annular fins of different cross-section shapes. Int. J. of Heat Mass Transfer, 1989. 32: p. 1100-1110.

22. Lalot, S., C. Tournier, and M. Jensen, Fin efficiency of annular fins made of two materials. International journal of heat and mass transfer, 1999. 42(18): p. 3461-3467.

23. Mokheimer, E., et al., A spreadsheet solution of transient conduction in composite fins. International journal of energy research, 2002. 26(5): p. 383-397.

24. Xiong, D., et al., Heat conduction in two-dimensional disk models. Phys Rev E Stat Nonlin Soft Matter Phys, 2010. 82(3 Pt 1): p. 030101.

25. P, D. and DeWitt, Fundamentals of heat and mass transfer. 2002.

26. Tu, P., et al., Fin Efficiency of an Annular Fin Composed of a Substrate Metallic Fin and a Coating Layer. Journal of Heat Transfer, 2006. 128(8): p. 851. 
27. Arfken, G., Bessel Functions of the First Kind, JV(x)" and "Orthogonality." Mathematical Methods for Physicists, 1985: p. 573-591 and 591-596.

28. Arfken, G., Neumann Functions, Bessel Functions of the Second Kind, Nv(x). Mathematical Methods for Physicists, 1985: p. 596-604.

29. Rezaey;, R., et al., Fabrication of wire mesh heat exchangers for waste heat recovery using wire arc spraying. Journal of Thermal Spray Technology, 2014. 